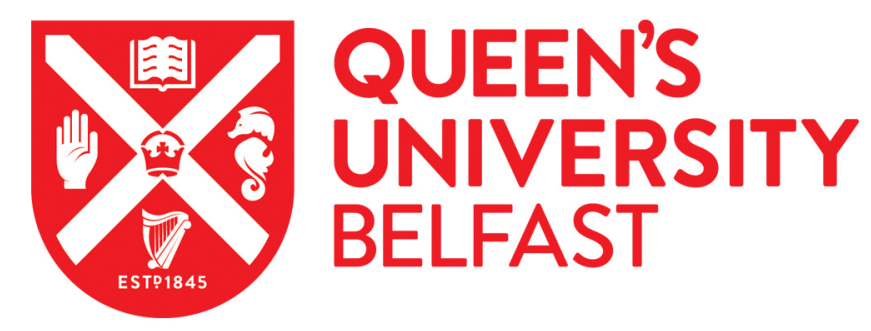

\title{
Trends in obesity and energy supply in the WHO MONICA project
}

Silventoinen, K., Sans, S., Tolonen, H., Monterde, D., Kuulasmaa, K., Kesteloot, H., Tuomilehto, J., \& Evans, A. (2004). Trends in obesity and energy supply in the WHO MONICA project. International Journal of Obesity, 28(5), 710-718. https://doi.org/10.1038/sj.ijo.0802614

\section{Published in:}

International Journal of Obesity

\section{Queen's University Belfast - Research Portal:}

Link to publication record in Queen's University Belfast Research Portal

\section{General rights}

Copyright for the publications made accessible via the Queen's University Belfast Research Portal is retained by the author(s) and / or other copyright owners and it is a condition of accessing these publications that users recognise and abide by the legal requirements associated with these rights.

Take down policy

The Research Portal is Queen's institutional repository that provides access to Queen's research output. Every effort has been made to ensure that content in the Research Portal does not infringe any person's rights, or applicable UK laws. If you discover content in the Research Portal that you believe breaches copyright or violates any law, please contact openaccess@qub.ac.uk. 


\title{
Trends in obesity and energy supply in the WHO MONICA Project
}

\author{
K Silventoinen ${ }^{1,2 *}$, S Sans ${ }^{3}$, H Tolonen ${ }^{4}$, D Monterde ${ }^{5}$, K Kuulasmaa $^{4}$, H Kesteloot $^{6}$ and \\ $\mathrm{J} \mathrm{Tuomilehto}^{1,4}$ for the WHO MONICA Project ${ }^{7}$
}

${ }^{1}$ Department of Public Health, University of Helsinki, Finland; ${ }^{2}$ Division of Epidemiology, School of Public Health, University of Minnesota, USA; ${ }^{3}$ Institute of Health Studies, Department of Health and Social Security, Barcelona, Spain; ${ }^{4}$ Department of Epidemiology and Health Promotion, National Public Health Institute, Finland; ${ }^{5}$ Saint Paul's Hospital Research Institute, Barcelona, Spain; and ${ }^{6}$ Department of Epidemiology, University of Leuven, Belgium

OBJECTIVE: To examine the relationship between secular trends in energy supply and body mass index (BMI) among several countries.

DESIGN: Aggregate level analyses of annually reported country food data against anthropometric data collected in independent cross-sectional samples from 34 populations in 21 countries from the early 1980s to the mid-1990s.

SUBJECTS: Population randomly selected participants aged 35-64y.

MEASUREMENTS: BMI data were obtained from the WHO MONICA Project. Food energy supply data were derived from the Food Balance Sheet of the Food and Agriculture Organization of the United Nations.

RESULTS: Mean BMI as well as the prevalence of overweight (BMI $\geq 25 \mathrm{~kg} / \mathrm{m}^{2}$ ) increased in virtually all Western European countries, Australia, the USA, and China. Decreasing trends in BMI were seen in Central and Eastern European countries. Increasing trends in total energy supply per capita were found in most high-income countries and China while decreasing trends existed in Eastern European countries. Between country differences in temporal trends of total energy supply per capita explained $41 \%$ of the variation of trends in mean BMI; the effect was similar upon the prevalence of overweight and obesity. Trends in percent of energy supply from total fat per capita had a slight effect on the trends in mean $\mathrm{BMI}\left(+7 \%\right.$ increment in $R^{2}$ ) when the total energy supply per capita was adjusted for, while energy supply from total sweeteners per capita had no additional effect.

CONCLUSION: Increasing energy supply is closely associated with the increase of overweight and obesity in western countries. This emphasizes the importance of dietary issues when coping with the obesity epidemic.

International Journal of Obesity (2004) 28, 710-718. doi:10.1038/sj.ijo.0802614

Published online 9 March 2004

Keywords: BMI; nutrition; energy; temporal trends; international

\section{Introduction}

During the last decades obesity has become a major public health problem. The prevalence of obesity has increased in the USA, ${ }^{1}$ Europe, ${ }^{2}$ and many low-income countries. ${ }^{3}$ In the USA, the rise in obesity has been especially rapid in the $1980 \mathrm{~s}$ and the 1990s, ${ }^{4}$ and obesity has increased also among children and adolescents ${ }^{5}$ suggesting that the increase in obesity in adults is likely to accelerate in the near future.

${ }^{*}$ Correspondence: K Silventoinen, Department of Public Health, University of Helsinki, PO Box 41, Mannerheimintie 172, FIN-00014, Finland. E-mail: karri.silventoinen@helsinki.fi

7Participating centres of the WHO MONICA Project listed in the appendix Received 26 September 2003; revised 11 December 2003; accepted 18 January 2004
Obesity is associated with many diseases, such as cardiovascular disease, ${ }^{6}$ type II diabetes, ${ }^{7}$ functional disability, ${ }^{8}$ musculo-skeletal disorders, ${ }^{9}$ and it is also associated with socioeconomic deprivation within a population. ${ }^{10}$ As a result, both the direct and indirect costs due to obesity for a society are huge. ${ }^{11}$

For the control of the epidemic of obesity one of the major questions is: which are the factors causing the upward trends in obesity? Increasing trends in sedentary lifestyle ${ }^{12,13}$ and possibly also in smoking cessation ${ }^{14-16}$ have contributed to the epidemic. The studies about the effects of variation in energy intake on trends in obesity have, however, remained inconclusive. Some findings have stipulated that in the USA energy intake per capita has decreased simultaneously with the increase in obesity. ${ }^{17,18}$ However, most studies thus far 
were limited by cross-sectional design and self-reported energy intake estimates, which are prone to several biases that may confound the results. ${ }^{19}$ Other studies based on aggregate level data ${ }^{20}$ as well as population surveys ${ }^{21}$ have suggested that the real energy supply has actually increased in the USA. The role of dietary fat ${ }^{22}$ and $\operatorname{sugar}^{23}$ intake in increasing obesity trends have also been considered suggestive but nonconclusive.

In this study, we present 10-year trends in mean body mass index (BMI, $\mathrm{kg} / \mathrm{m}^{2}$ ) and in prevalence of overweight and obesity. In addition, we assess the ecological relation between secular trends in mean BMI and macronutrient energy supply among several countries. The main research question is: how much of the between-country variation in temporal trends in mean BMI is explained by differences in trends in the per capita daily total energy supply. In addition, we explore whether the trends in the energy supply from all sweeteners and total fat had an effect on the trends in mean BMI over and above the changes in total energy supply.

\section{Methods}

The anthropometric data were derived from the WHO MONICA (Multinational MONItoring of trends and determinants in CArdiovascular disease) Project $^{24}$ designed to monitor temporal changes in classic risk factors of cardiovascular diseases in the general population aged 35-64 y. The study was carried out in 21 countries from the early 1980 s to the mid-1990s in independent cross-sectional samples in two or three surveys during the study period. A uniform study protocol was applied, but there were slight variations in the survey years between the populations (Table 1). Data were collected by the MONICA centres according to the principles of the Declaration of Helsinki and following their local ethical requirements at the time of the data collection. All survey participants gave their consent for the use of their data in the WHO MONICA Project. Four MONICA populations were excluded from this paper: One due to inadequate quality of anthropometric measurements ${ }^{25}$ and three due to low response rates. ${ }^{26} \mathrm{~A}$ total of 34 populations were finally used for the analysis. Response rates in the populations included in this study varied from 49 to $90 \%$ (Table 1 ).

Height and weight were measured in light clothing and without shoes. Height was measured in a standing position, and the measurements were rounded to the nearest centimeter. Weight was measured using a beam balance scale and rounded to the nearest 200 grams. $^{27}$ Four centers used another type of scales: Belfast, Glasgow and Toulouse used a digital scale and Gothenburg used a balance scale in the first survey and a digital scale in the other two surveys. ${ }^{25}$ BMI was used as an indicator of relative weight and obesity. Conventional cutpoints were used to classify people as overweight $\left(\mathrm{BMI} \geq 25 \mathrm{~kg} / \mathrm{m}^{2}\right.$ ) or obese $\left(\mathrm{BMI} \geq 30 \mathrm{~kg} / \mathrm{m}^{2}\right) .{ }^{28}$ Smoking status was assessed by MONICA survey protocol questionnaires. ${ }^{27}$

Annual data on per capita total energy supply, and energy supply from all sweeteners and total fat for each country were obtained from the Food Balance Sheets of the Food and Agriculture Organization of the United Nations (FAO) ${ }^{29}$ These are periodic statistics giving the total quantity of foodstuffs produced in a country added to the total quantity imported and adjusted to any change in stocks that may have occurred during the year giving the available annual supply. A distinction is made between the quantities exported, quantities consumed not for human nutrition, and food supplies available for human consumption. The per capita supply of each food item available for human consumption is then obtained by dividing the corresponding quantity by the related data on the population. Given the boundary changes that occurred in Eastern Europe during the study period, some assumptions had to be made for the following countries: For Russia, data from the whole ex-USSR were used for the years 1984-1991 and for the Russian Federation for the years 1992-1995. For Lithuania, data for the whole ex-USSR was used for the years 1983-1991 and for Lithuania itself for the years 1992-1993. For Yugoslavia, data were for the ex-Yugoslavia for 1984-1991 and for the Republic of Yugoslavia for the years 1992-1995.

Average annual trends in BMI and obesity were derived for each 10-year age group of each population from a simple linear regression of the individual observations on the date of examinations using sex as covariate. All results were adjusted for age by direct age standardization using the world population as the standard population in 10-year age categories. ${ }^{30}$ Annual trends in countrywide energy supply and energy from total fat and all sweeteners expressed both as absolute kilocalories per capita and day (kcal/cap/day) and as percentage of total energy were obtained by linear regression on calendar year for each country with a MONICA population described in Table 1. Regression coefficients were multiplied by 10 or by their specific MONICA population period of observation to estimate 10 year or whole period trends. A linear regression model at the aggregate level was then used to study the association of trends in total energy supply per capita with trends in the obesity indexes. ${ }^{31}$ As the nutrition data were not age and sex specific, the results were reported for both sexes together. The age and sex adjusted annual trends in mean BMI and in the prevalence of overweight and obesity in each MONICA population were used as dependent variables, using the annual changes in the daily per capita total energy supply and the energy from all sweeteners and total fat in each country expressed in absolute $\mathrm{kcal} / \mathrm{capita} /$ day as explanatory variables. We also tested whether the trends in proportion of ex-smokers had an additional effect on the association between trends in total energy supply per capita and obesity. The error term of the regression model was defined as the sum of the error due to the known standard error (s.e.) of the estimates of trends of the obesity indexes and the error representing the variation not explained by the model. When the percentages of variation explained by the trends in total energy supply per capita and smoking were computed, the variation attributable to the known s.e. of the estimates of trends in 
Table 1 Study years, number of participants and response rates in three independent surveys in the MONICA populations

\begin{tabular}{|c|c|c|c|c|c|c|c|c|c|c|}
\hline \multirow[t]{2}{*}{ Country } & \multirow[t]{2}{*}{ Population (abbreviation) } & \multicolumn{3}{|c|}{ Survey periods } & \multicolumn{3}{|c|}{ Number of participants } & \multicolumn{3}{|c|}{ Response rates (\%) ${ }^{\mathrm{a}}$} \\
\hline & & Initial & Middle & Final & Initial & Middle & Final & Initial & Middle & Final \\
\hline \multirow[t]{2}{*}{ Australia } & Newcastle (AUS-NEW) & 1983 & 1988-89 & 1994 & 2459 & 1343 & 1325 & 68 & 63 & 64 \\
\hline & Perth (AUS-PER) & 1983 & 1989 & 1994 & 1292 & 604 & 579 & 81 & 73 & 68 \\
\hline Belgium & Ghent (BEL-GHE) & $1985-87$ & $1988-90$ & 1990-92 & 766 & 689 & 739 & 54 & 49 & 52 \\
\hline China & Beijing (CHN-BEI) & 1984-85 & 1988-89 & 1993 & 1244 & 1215 & 1123 & 89 & 78 & 70 \\
\hline Czechoslovakia & Czech republic (CZE-CZE) & 1985 & 1988 & 1992 & 1933 & 2102 & 1837 & 85 & 86 & 77 \\
\hline Denmark & Glostrup (DEN-GLO) & $1982-84$ & $1986-87$ & 1991-92 & 2816 & 1142 & 1217 & 79 & 76 & 74 \\
\hline \multirow[t]{3}{*}{ Finland } & Kuopio province (FIN-KUO) & 1982 & 1987 & 1992 & 1966 & 1206 & 1177 & 85 & 83 & 81 \\
\hline & North Karelia (FIN-NKA) & 1982 & 1987 & 1992 & 2385 & 2309 & 1103 & 80 & 81 & 77 \\
\hline & Turku/Loimaa (FIN-TUL) & 1982 & 1987 & 1992 & 2484 & 1139 & 1196 & 85 & 79 & 82 \\
\hline \multirow[t]{2}{*}{ France } & Lille (FRA-LIL) & 1986-89 & - & 1995-96 & 1171 & - & 1142 & 68 & - & 73 \\
\hline & Toulouse (FRA-TOU) & 1985-87 & 1988-91 & 1994-96 & 1319 & $586^{\mathrm{b}}$ & 1174 & 59 & 59 & 59 \\
\hline \multirow[t]{4}{*}{ Germany } & Augsburg (rural) (GER-AUR) & 1984-85 & 1989-90 & 1994-95 & 1619 & 1645 & 1683 & 82 & 79 & 80 \\
\hline & Augsburg (urban) (GER-AUU) & 1984-85 & 1989-90 & 1994-95 & 1384 & 1343 & 1317 & 76 & 73 & 71 \\
\hline & Bremen (GER-BRE) & 1984 & 1988 & 1991-92 & 1289 & 868 & 824 & 71 & 69 & 66 \\
\hline & East Germany (GER-EGE) & $1982-84$ & 1988 & 1993-94 & 818 & 848 & 919 & 90 & 77 & 58 \\
\hline Iceland & Iceland (ICE-ICE) & 1983 & 1988-89 & 1993-94 & 686 & 677 & 692 & 76 & 73 & 79 \\
\hline \multirow[t]{2}{*}{ Italy } & Area Brianza (ITA-BRI) & 1986-87 & 1989-90 & 1993-94 & 1257 & 1225 & 1306 & 70 & 69 & 72 \\
\hline & Friuli (ITA-FRI) & 1986 & 1989 & 1994 & 1436 & 1391 & 1373 & 80 & 78 & 77 \\
\hline Lithuania & Kaunas (LTU-KAU) & 1983-85 & $1986-87$ & 1992-93 & 1463 & 1762 & 1231 & 69 & 66 & 57 \\
\hline New Zealand & Auckland (NEZ-AUC) & 1982 & - & 1993-94 & 1587 & - & 1397 & 81 & - & 62 \\
\hline \multirow[t]{2}{*}{ Poland } & Tarnobrzeg Voivodship (POL-TAR) & 1983-84 & $1987-88$ & 1992-93 & 2667 & 1288 & 1310 & 81 & 73 & 75 \\
\hline & Warsaw (POL-WAR) & $1984^{c}$ & $1988^{d}$ & 1993 & 2624 & 1418 & 1514 & 74 & 76 & 77 \\
\hline \multirow[t]{3}{*}{ Russia } & Moscow Control (RUS-MOC) & 1984-86 & 1988-89 & $1992-95$ & 1416 & 1201 & 1083 & 78 & 73 & 66 \\
\hline & Novosibirsk Control (RUS-NOC) & 1985-86 & 1988-89 & 1995 & 1178 & 1169 & 1184 & 70 & 68 & 70 \\
\hline & Novosibirsk Intervention (RUS-NOI) & 1985 & 1988 & 1994-95 & 1267 & 1264 & 1267 & 73 & 73 & 72 \\
\hline Spain & Catalonia (SPA-CAT) & $1986-88$ & 1990-92 & 1994-96 & 1979 & 2104 & 2605 & 76 & 69 & 74 \\
\hline \multirow[t]{2}{*}{ Sweden } & Gothenburg (SWE-GOT) & 1985-86 & 1990-91 & 1994-96 & 1039 & 1244 & 1282 & 74 & 72 & 66 \\
\hline & Northern Sweden (SWE-NSW) & 1986 & 1990 & 1994 & 1255 & 1211 & 1162 & 84 & 83 & 80 \\
\hline \multirow[t]{2}{*}{ Switzerland } & Ticino (SWI-TIC) & 1984-85 & 1988-89 & 1992-93 & 1550 & 1454 & 1500 & 79 & 74 & 76 \\
\hline & Vaud/Fribourg (SWI-VAF) & 1984-85 & 1988-89 & 1992-93 & 1188 & 1279 & 1148 & 61 & 64 & 57 \\
\hline \multirow[t]{2}{*}{ UK } & Belfast (UNK-BEL) & 1983-84 & 1986-87 & 1991-92 & 1849 & 1815 & 1608 & 57 & 58 & 48 \\
\hline & Glasgow (UNK-GLA) & 1986 & 1992 & 1995 & 976 & 1188 & 1401 & 51 & 56 & 58 \\
\hline USA & Stanford (USA-STA) & 1979-80 & $1985-86$ & $1989-90$ & 952 & 1026 & 1008 & 68 & 58 & 59 \\
\hline Yugoslavia & Novi Sad (YUG-NOS) & 1984 & 1988-89 & 1994-95 & 1182 & 1197 & 982 & 82 & 83 & 76 \\
\hline
\end{tabular}

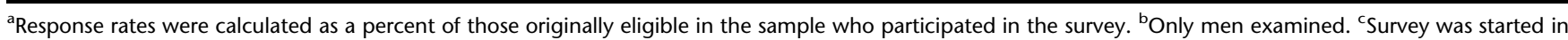
December 1983 and finished in January 1985. 'Survey was finished in January 1989. - Survey not done.

mean BMI and in prevalence of overweight and obesity was omitted. ${ }^{32}$ Pearson and Spearman coefficients were used to calculate linear correlations between 10-year trends. The analyses were carried out using the SAS statistical package ${ }^{33}$ at the MONICA Data Centre, National Public Health Institute in Helsinki, Finland in collaboration with the Institutes in Barcelona, Spain.

\section{Results}

Table 2 gives the baseline situation and 10-year trends in total energy supply per capita and in the proportion of energy from total fat and all sweeteners in each country with the MONICA populations. Total energy supply per capita at the baseline was lowest in China where also the proportion of energy from all sweeteners and total fat was low compared with the other countries. There was some variation in total energy supply per capita among the other countries, but no clear geographic pattern was seen. The proportion of energy from all sweeteners was the lowest in the Mediterranean countries, Spain, Italy, and France, and the proportion of energy from total fat was somewhat lower in Eastern than Western European countries

Figure 1 shows the estimated linear changes in total energy supply per capita and energy supply per capita from all sweeteners, total fat, and all other macronutrients, expressed in absolute $\mathrm{kcal} / \mathrm{cap} /$ day during the entire specific periods of each MONICA population for each country. In most Western European countries, the USA, Australia, New Zealand, and China energy supply increased. The increase was largest in the USA where the estimated rise in daily energy supply during $12 \mathrm{y}$ was $376 \mathrm{kcal}$ per capita on average. A decrease in energy supply was found in Central and Eastern European countries and it was steepest in Yugoslavia and Russia. The detailed study of the time series showed that these decreases took place soon after the beginning of the 1990s (data not shown). A slight decrease in total energy supply was also found in some Western European countries. As expected, changes in energy from all sweeteners and total fat showed a 
Table 2 Total energy supply (kcal/capita/day) and proportion of energy from sweeteners and fat in the MONICA countries

\begin{tabular}{|c|c|c|c|c|c|c|c|}
\hline & \multirow[t]{2}{*}{ Years } & \multicolumn{3}{|c|}{ Baseline year } & \multicolumn{3}{|c|}{ 10-year trend in } \\
\hline & & Total energy & $\%$ from all sweeteners & $\%$ from total fat & Total energy & $\%$ from all sweeteners & $\%$ from total fat \\
\hline Australia & 1983-94 & 3102 & 16 & 35 & 73 & -1.6 & 3.3 \\
\hline Belgium & 1985-92 & 3439 & 11 & 40 & 287 & 1.2 & -0.4 \\
\hline China & 1984-93 & 2622 & 2 & 14 & 115 & -0.1 & 6.5 \\
\hline Czechoslovakia & 1985-92 & 3438 & 11 & 34 & 277 & 4.1 & -2.5 \\
\hline Denmark & 1982-92 & 3092 & 15 & 38 & 225 & -1.8 & 0.9 \\
\hline Finland & 1982-92 & 3109 & 11 & 39 & 180 & 1.5 & -3.1 \\
\hline France & $1986-96$ & 3475 & 9 & 40 & 4 & 0.7 & 1.3 \\
\hline France & $1985-96$ & 3498 & 10 & 40 & 16 & 0.7 & 1.6 \\
\hline Germany & 1984-95 & 3412 & 12 & 36 & -97 & 0.3 & 2.1 \\
\hline Germany & 1984-92 & 3412 & 12 & 36 & -35 & 0.0 & 2.7 \\
\hline Germany & $1982-94$ & 3363 & 13 & 37 & -34 & -0.4 & 2.0 \\
\hline Iceland & 1983-94 & 3188 & 17 & 38 & -139 & 1.2 & -3.6 \\
\hline Italy & $1986-94$ & 3495 & 8 & 37 & -36 & 0.7 & 0.3 \\
\hline Lithuania $^{\mathrm{a}}$ & 1983-93 & 3387 & 14 & 26 & -480 & -4.1 & -0.4 \\
\hline New Zealand & $1982-94$ & 3107 & 15 & 35 & 247 & -0.1 & -1.4 \\
\hline Poland & 1983-93 & 3376 & 14 & 29 & -14 & -1.8 & 1.2 \\
\hline Russia $^{a}$ & 1984-95 & 3380 & 14 & 26 & -548 & -3.0 & -2.4 \\
\hline Russia $^{a}$ & 1985-95 & 3373 & 13 & 27 & -612 & -3.3 & -3.2 \\
\hline Spain & 1986-96 & 3061 & 8 & 36 & 200 & 1.1 & 2.8 \\
\hline Sweden & 1985-96 & 2982 & 15 & 37 & 192 & 0.0 & -0.4 \\
\hline Sweden & 1986-94 & 2961 & 14 & 38 & 288 & 1.1 & -1.4 \\
\hline Switzerland & 1984-93 & 3362 & 14 & 41 & -85 & 0.0 & -0.7 \\
\hline UK & 1983-92 & 3130 & 14 & 39 & 113 & -0.8 & -0.1 \\
\hline UK & $1986-95$ & 3203 & 12 & 39 & -218 & -1.1 & 0.9 \\
\hline USA & 1979-90 & 3203 & 18 & 36 & 314 & -0.8 & -0.4 \\
\hline Yugoslavia & 1984-95 & 3635 & 10 & 27 & -821 & -3.5 & 9.2 \\
\hline
\end{tabular}

${ }^{a}$ USSR data are until the year 1992.

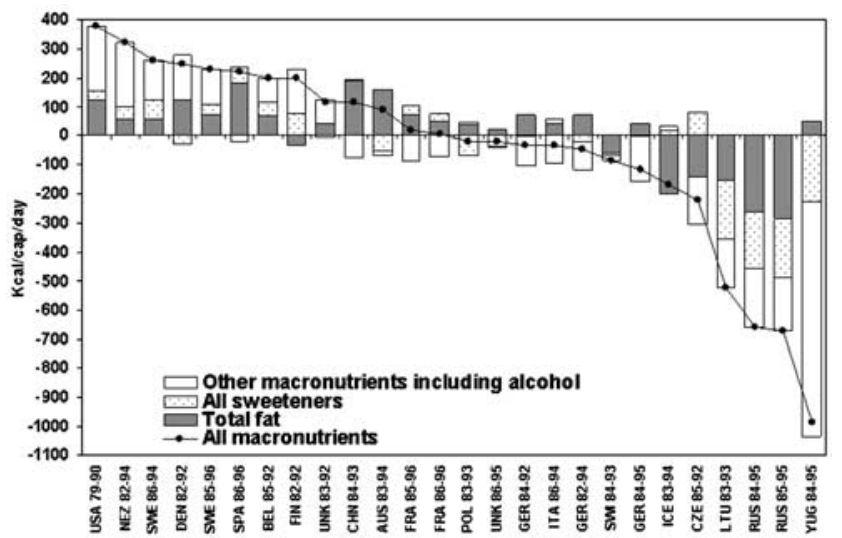

Figure 1 Estimated linear change in country's energy supply (kcal/capita/ day) during MONICA periods.

high correlation with the change in total energy supply (Spearman $\rho$ for all sweeteners $=0.61, P<0.0001$ and total fat $=0.68, \quad P<0.0001)$ and a very similar geographical pattern.

Table 3 presents the 10 -year trends in mean BMI and in the prevalence of overweight and obesity. Mean BMI increased in most populations; the largest changes were found in Australia (Newcastle) and the USA (Stanford) where it was $1.5 \mathrm{~kg} / \mathrm{m}^{2}$ over $10 \mathrm{y}$. Decreasing trends in BMI were found in
Russia and Central European populations. In Western European countries, a decrease in BMI was found only in Switzerland (Ticino) and in Italy (Friuli). The largest increases in the prevalence of overweight were observed in Australia (Newcastle) and the USA (Stanford) and the largest decreases were found in Russia (Moscow) and Yugoslavia (Novi Sad).

Figure 2 shows the ecological linear correlation between 10 -year trends of total and the two specific macronutrients energy supply per capita and the three indexes of obesity. Trends in total energy and energy from total fat and all sweeteners per capita were strongly correlated with trends in the three obesity measures. However, when we studied the associations between mean BMI and the portion of total energy instead of absolute energy, we did not find statistically significant associations (Spearman $\rho$ for all sweeteners $=0.19, P<0.27$ and total fat $=0.23, P<0.19$ ).

Table 4 presents the results of the ecological multiple regression analysis. Secular trends in total energy supply per capita explained $41 \%$ of the between population differences in trends of BMI; A differential annual change of $10 \mathrm{kcal} / \mathrm{cap} /$ day in energy supply produced an across populations difference of $0.15 \mathrm{~kg} / \mathrm{m}^{2}$ in the 10 -year trends of mean BMI (95\% CI 0.08-0.22). This would correspond to a $1.8 \%$ increase in the prevalence of overweight and a $0.9 \%$ increase in the prevalence of obesity during a 10-year period. Prevalence of ex-smokers explained also a part of this 
Table 3 Mean BMI and 10-year trends in BMI, prevalence of overweight, and of obesity in the MONICA populations ${ }^{a}$

\begin{tabular}{|c|c|c|c|c|c|c|}
\hline & \multicolumn{3}{|c|}{ Mean $B M I$ in the surveys ${ }^{\mathrm{b}}$} & \multicolumn{3}{|c|}{ 10-year trends in } \\
\hline & Initial & Middle & Final & Mean BMI & $\%$ oveweight & $\%$ obese \\
\hline \multicolumn{7}{|l|}{ Population } \\
\hline AUS-NEW & 26.0 & 26.9 & 27.6 & 1.5 & 11.6 & 8.8 \\
\hline AUS-PER & 25.2 & 25.9 & 26.3 & 1.0 & 7.9 & 6.0 \\
\hline BEL-GHE & 26.1 & 25.9 & 26.2 & 0.3 & 7.0 & 2.9 \\
\hline CHN-BEI & 24.0 & 24.3 & 24.3 & 0.4 & 4.3 & -0.7 \\
\hline CZE-CZE & 27.9 & 28.3 & 27.7 & -0.3 & -3.4 & -1.3 \\
\hline DEN-GLO & 25.1 & 25.1 & 25.4 & 0.3 & 0.5 & 2.0 \\
\hline FIN-KUO & 26.7 & 27.0 & 27.2 & 0.5 & 1.4 & 5.7 \\
\hline FIN-NKA & 27.0 & 27.2 & 27.3 & 0.2 & 1.3 & 2.5 \\
\hline FIN-TUL & 26.5 & 27.0 & 26.7 & 0.3 & 1.7 & 3.2 \\
\hline FRA-LIL & 25.7 & - & 26.4 & 0.7 & 3.0 & 3.9 \\
\hline FRA-TOU & 25.2 & 26.2 & 25.3 & 0.2 & 1.2 & 1.9 \\
\hline GER-AUR & 27.1 & 27.1 & 27.3 & 0.3 & 1.4 & 2.6 \\
\hline GER-AUU & 26.6 & 26.3 & 26.8 & 0.3 & 1.4 & 2.7 \\
\hline GER-BRE & 26.4 & 26.6 & 26.5 & 0.2 & -0.8 & 1.8 \\
\hline GER-EGE & 26.2 & 26.3 & 26.7 & 0.5 & 4.3 & 1.7 \\
\hline ICE-ICE & 25.2 & 25.8 & 26.6 & 1.3 & 13.8 & 6.5 \\
\hline ITA-BRI & 25.4 & 25.9 & 26.0 & 0.7 & 8.0 & 2.8 \\
\hline ITA-FRI & 26.5 & 26.4 & 26.3 & -0.2 & -0.9 & 1.3 \\
\hline LTU-KAU & 28.8 & 28.6 & 27.5 & -1.4 & -15.2 & -9.0 \\
\hline NEZ-AUC & 25.1 & - & 26.2 & 1.0 & 8.7 & 5.9 \\
\hline POL-TAR & 26.7 & 26.9 & 27.2 & 0.6 & 3.9 & 3.1 \\
\hline POL-WAR & 27.1 & 27.2 & 27.3 & 0.2 & 0.2 & 3.9 \\
\hline RUS-MOC & 27.3 & 27.6 & 25.8 & -1.5 & -15.8 & -7.8 \\
\hline RUS-NOC & 28.0 & 28.4 & 27.2 & -0.9 & -9.9 & -4.6 \\
\hline RUS-NOI & 27.8 & 27.5 & 27.7 & 0.0 & -2.9 & 1.2 \\
\hline SPA-CAT & 26.6 & 27.3 & 27.0 & 0.6 & 3.5 & 4.9 \\
\hline SWE-GOT & 24.9 & 25.3 & 25.5 & 0.6 & 2.7 & 2.3 \\
\hline SWE-NSW & 25.7 & 25.8 & 26.0 & 0.5 & 5.5 & 1.6 \\
\hline SWI-TIC & 26.3 & 25.2 & 25.9 & -0.4 & -3.2 & -2.8 \\
\hline SWI-VAF & 25.6 & 25.7 & 25.6 & 0.0 & 0.1 & 0.1 \\
\hline UNK-BEL & 25.7 & 25.9 & 26.9 & 0.3 & 2.8 & 2.5 \\
\hline UNK-GLA & 25.9 & 26.5 & 26.8 & 1.0 & 7.9 & 10.3 \\
\hline USA-STA & 25.3 & 26.2 & 26.8 & 1.5 & 11.1 & 9.5 \\
\hline YUG-NOS & 27.4 & 27.4 & 27.5 & 0.2 & -12.0 & -1.5 \\
\hline
\end{tabular}

- Survey not done. ${ }^{\mathrm{a} D a t a}$ are presented for men and women together. ${ }^{\mathrm{b}}$ Standardized by age and sex.

association, and together with energy supply it explained $51 \%$ of the differences in change of mean BMI and $69 \%$ of the differences in change of prevalence of overweight. We continued the analyses by studying the additional effect of the trends of calories supplied from all sweeteners and total fat per capita on trends in mean BMI and the prevalence of obesity when the total energy supply per capita was adjusted for. Trends in all sweeteners had no independent effect on the trends of any of the three parameters, while trends in energy from total fat per capita had a slight independent effect on the trends in mean BMI $\left(0.21 \mathrm{~kg} / \mathrm{m}^{2}\right.$ for $100 \mathrm{kcal} /$ capita/day, 95\% CI 0.00-0.43) increasing the explained variance in BMI trends by $7 \%$ over and above the change in the total energy supply per capita.

\section{Discussion}

Our results suggest that increased energy supply per capita is an important determinant of the current increasing trends of the population mean of BMI and of the prevalence of overweight and obesity. The energy supply data, based on the FAO Food Balance Sheets, show that the energy supply per capita has increased in most Western European countries, the USA, Australia, New Zealand, and China. This is in contrast to some previous speculations that energy intake may have even decreased in the USA. ${ }^{17,18}$ It is possible that a recall bias influenced these earlier results as they were based on individual reporting of previous history. This recall bias may also have increased over time since food portion sizes have increased in the USA during the last two decades. ${ }^{34}$

The energy data derived from the FAO Food Balance Sheets combined to the anthropometrical data collected by health surveys used in our analysis also have obvious and wellknown limitations. Since the FAO nutritional data cannot take account the waste of foodstuff, the energy supply per capita is overestimated. However, in this study we have studied primarily trends rather than the absolute supply of energy per capita. Waste of foodstuff may have increased in the 1980s and the 1990s when living standard has increased in most of the countries, and thus the change in the real energy supply per capita might have been slightly overestimated. It is further possible that in Eastern Europe, which suffered economic difficulties during the study period, waste of foodstuff decreased. This bias may have thus overestimated differences in energy supply per capita between the countries. However, it is probable that waste of foodstuff in Eastern Europe during transportation and conservation is higher than in Western Europe. Also, we cannot exclude the possibility that change in living standard has simultaneously resulted in decreased physical activity, which could modify the association between the energy supply and BMI. Nevertheless, the FAO data were shown to correlate well with energy and macronutrient intake estimated from population surveys. ${ }^{35}$ The response rates do not follow a clear geographic pattern, and although in some countries they decreased to suboptimal levels, in most populations they remained reasonable stable and thus they are unlikely to bias the estimates of obesity trends. It is also worth noting that while the FAO data refer to whole countries and entire age spectrum, the BMI data in this study are based on geographically limited populations aged 35-64 y. Although it is probable that within-countries regional and age heterogeneity in diet and energy supply exists, it is likely that it is by far smaller than the between-country heterogeneity. Our nutritional and anthropometric data are thus not strictly comparable, but this is the best possible way to examine the relationship at the ecological level with the existing information for that period. Only linear trends were considered in the analysis. For obesity, any estimates of nonlinearity would be imprecise, and the uncertainties described above on the data on food-supply outweigh the importance of considering possible nonlinearity in the trends in food-supply. To summarize, our data have several limitations but they are unlikely to strengthen the associa- 
All macronutrients
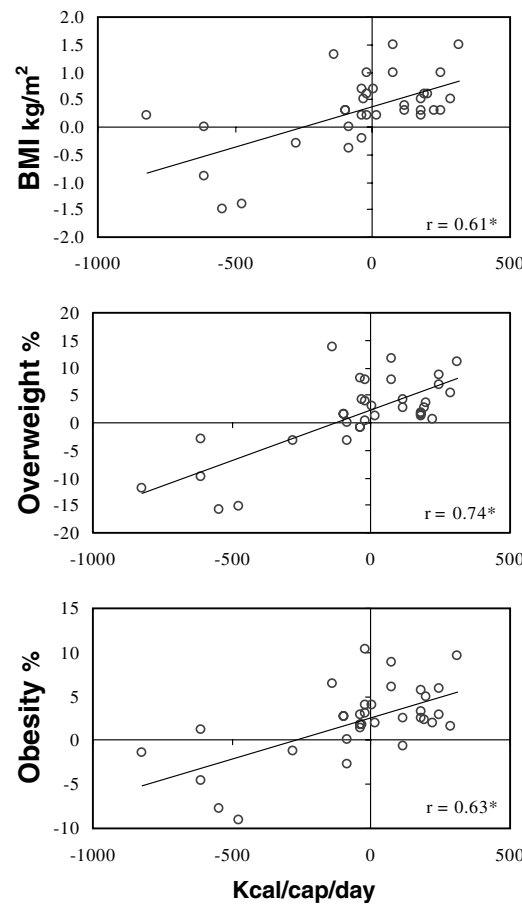

* $p<0.01$
Total fat
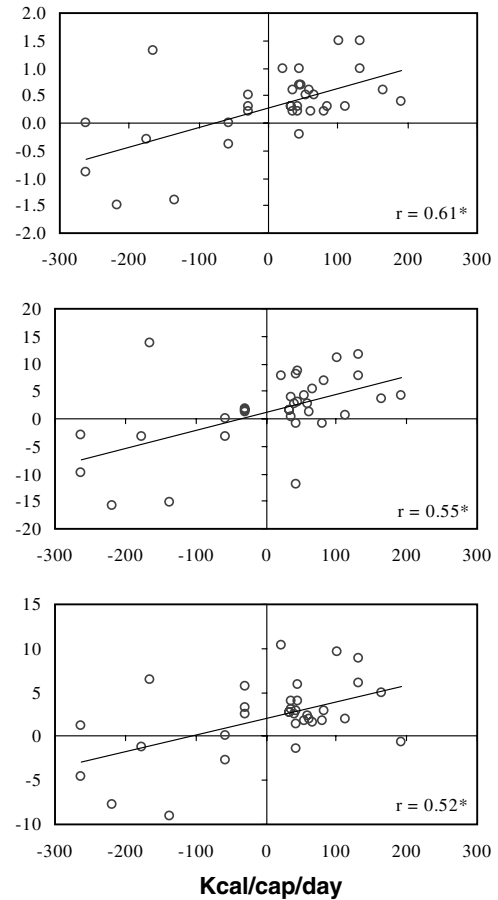

All sweeteners
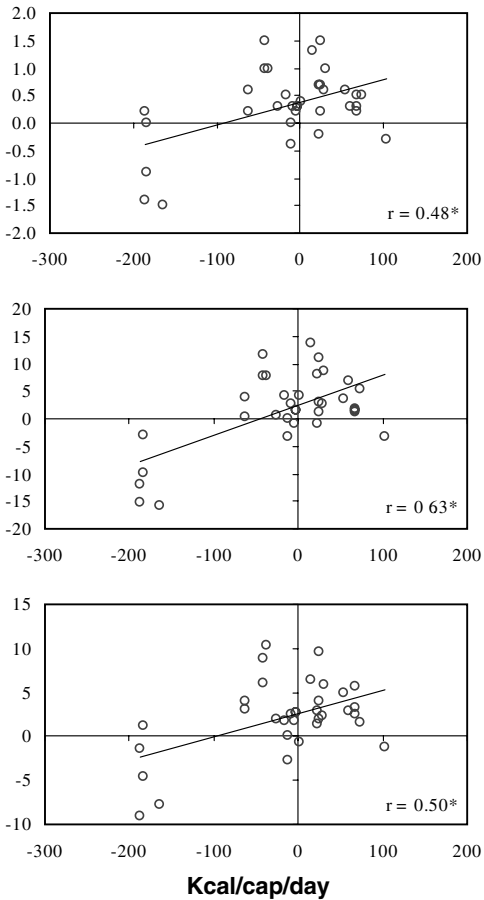

Figure 2 Correlations between 10-year trends of country's energy supply and of indexes of obesity in MONICA populations.

Table 4 Linear regression of annual trends of total, sweeteners and fat energy supply $(100 \mathrm{kcal} / \text { capita/day })^{\mathrm{a}}$ on trends of $\mathrm{BMI}\left(\mathrm{kg} / \mathrm{m}^{2}\right)$, overweight $(\%)$ and obesity (\%)

\begin{tabular}{|c|c|c|c|}
\hline & Coefficient & $95 \% \mathrm{Cl}$ & Explained variation (\%) \\
\hline \multicolumn{4}{|l|}{ Mean BMI } \\
\hline Change in total daily energy supply & 0.15 & $(0.08,0.22)$ & 41 \\
\hline Change in total daily energy supply ${ }^{b}$ & 0.10 & $(0.03,0.18)$ & 51 \\
\hline Change in total daily energy supply from all sweeteners ${ }^{c}$ & -0.04 & $(-0.46,0.37)$ & +0 \\
\hline Change in total daily energy supply from total fat ${ }^{\mathrm{c}}$ & 0.21 & $(0.00,0.43)$ & +7 \\
\hline \multicolumn{4}{|l|}{ Overweight (BMI $\geq 25 \mathrm{~kg} / \mathrm{m}^{2}$ ) } \\
\hline Change in total daily energy supply & 1.82 & $(1.24,2.41)$ & 61 \\
\hline Change in total daily energy supply ${ }^{b}$ & 1.38 & $(0.74,2.01)$ & 69 \\
\hline Change in total daily energy supply from all sweeteners ${ }^{c}$ & 0.45 & $(-3.12,4.01)$ & +0 \\
\hline Change in total daily energy supply from total fat ${ }^{\mathrm{c}}$ & 0.44 & $(-1.57,2.44)$ & +0 \\
\hline \multicolumn{4}{|l|}{ Obesity $\left(B M I \geq 30 \mathrm{~kg} / \mathrm{m}^{2}\right)$} \\
\hline Change in total daily energy supply & 0.92 & $(0.50,1.34)$ & 46 \\
\hline Change in total daily energy supply ${ }^{b}$ & 0.66 & $(0.20,1.12)$ & 56 \\
\hline Change in total daily energy supply from all sweeteners ${ }^{c}$ & -0.23 & $(-2.81,2.35)$ & +0 \\
\hline Change in total daily energy supply from total fat ${ }^{c}$ & 0.57 & $(-0.83,1.98)$ & +1 \\
\hline
\end{tabular}

${ }^{a}$ All models were weighted by standard error of the trend in BMI, the prevalence of overweight or obesity. ${ }^{b}$ Adjusted for trends in the prevalence of ex-smokers. 'Adjusted for total calories. The column for explained variation gives the increment after trends in total calories were already included in the model.

tions studied and thus the effect of nutrition on BMI in this study is rather under- than overestimated.

Decreasing trends in energy supply were found in Central and Eastern European countries. This decline took place rapidly at the beginning of the 1990 s and is probably associated with the dramatic economic and political changes in these countries. These might have influenced the reporting of the data to FAO, in addition to probable changes in food supply. It is also possible that these trends are biased due to an increase in private food production. In addition, 
we had to make certain assumptions for Russia, Lithuania, and Yugoslavia due to the boundary changes during the study period. Nonetheless, the results are in accordance with previous studies showing that poor nutrition and material deprivation are common in Eastern European countries, especially in Russia, ${ }^{36,37}$ and strongly suggest that the weight loss in those countries was unintentional and associated with widespread material deprivation. However, it is noteworthy that mean BMI in Eastern European countries was much higher than in Western Europe during the initial survey and still remained higher at the final survey in spite of the diverging temporal trends.

Increase in total energy supply per capita was common in many countries but for similar levels of change in total calories, the sources of change varied. For example, in Spain increase in energy intake was mainly due to increase of total fat and all sweeteners, while in Finland it was mainly through an increase in all other macronutrients as well as sweeteners. In China and Australia energy supply increased almost exclusively due to total fat. A complex global mosaic in disease trends beyond obesity could well emerge out of this diverse pattern of energy supply. The literature suggests that sucrose ingestion contributes to increase energy intake because its ingestion in small quantities fails to reduce food intake in human adults. ${ }^{38}$ The role of fat as a major determinant of mass obesity is not exempt from controversy either, ${ }^{39}$ but is better established. ${ }^{40}$ Whatever the source of energy, it is important to note that even small but persistent increases in energy supply will in the medium term lead unavoidably to an increase in body weight, unless the level of physical activity concomitantly increases to compensate the excess caloric intake. For instance, for an individual, a $100 \mathrm{kcal}$ daily increase in energy intake (a chocolate bar or two cookies) will result in an increase of $36500 \mathrm{kcal}$ per year which corresponds approximately to $5 \mathrm{~kg}$ body fat, ignoring the associated change in basal metabolic rate.

In the present study, strong ecological correlations were found between secular trends in total energy per capita and energy from total fat and all sweeteners per capita and changes in the mean BMI and in prevalence of overweight and obesity across populations. Changes in energy from sweeteners per capita added little to explain the changes in obesity once total energy per capita had been accounted for, while changes in the energy from total fat per capita had a slight effect on the trends in BMI. This is in accordance with findings from other studies at the individual level showing divergent results in the relationship of sugar intake with body weight, due to the reciprocity between the percentage of energy from sugar and fat. ${ }^{23}$ This problem is minimized when absolute rather than relative amount of calories are used for analysis like in this study. Trends in BMI and overweight were better explained when changes in total energy supply per capita and changes in the prevalence of exsmokers were considered together. Smoking has thermogenic effects and also reduces appetite and its effects on body weight are well documented. ${ }^{14,16}$ Nevertheless, it has been shown that smoking at present is associated with a cluster of other unhealthy lifestyles and smokers may no longer be less obese than nonsmokers. ${ }^{16}$

Our results suggest that avoidance of high-energy nutrients such as fat, starch, and sugar in habitual diets would be important means to control body weight. However, it is important to emphasize that a shift to lower the total energy intake is the essential measure in order to control the obesity pandemic. The changes in the ratios of macronutrient intake needed to achieve this public health goal should be country or region specific depending on their patterns of food supply and consumption. This obliges to characterize much better than is available until now dietary habits and the nutritional status of populations.

In conclusion, this large study in a variety of populations confirmed that secular changes in energy supply per capita are strongly associated with the trends in mean BMI and the prevalence of overweight and obesity. In the prevention of overweight, it is important to target dietary issues not only among the individuals but more so at the population level.

\section{Acknowledgements}

The MONICA Centres are funded predominantly by regional and national governments, research councils, and research charities. Coordination is the responsibility of the World Health Organization (WHO), assisted by local fund raising for congresses and workshops. WHO also supports the MONICA Data Centre (MDC) in Helsinki. Not covered by this general description is the ongoing generous support of the MDC by the National Public Health Institute of Finland, and a contribution to WHO from the National Heart, Lung, and Blood Institute, National Institutes of Health, Bethesda, MD, USA for support of the MDC and the Quality Control Centre for Event Registration in Dundee. The completion of the MONICA Project is generously assisted through a Concerted Action Grant from the European Community. Likewise appreciated are grants from ASTRA Hässle AB, Sweden, Hoechst AG, Germany, Hoffmann-La Roche AG, Switzerland, the Institut de Recherches Internationales Servier (IRIS), France, and Merck \& Co. Inc., NJ, USA, to support data analysis and preparation of publications. This work has been also supported by Academy of Finland (Grants \#46558 and \#53585).

\section{References}

1 Kuczmarski RJ, Flegal KM, Campbell SM, Johnson CL. Increasing prevalence of overweight among US adults. The National Health and Nutrition Examination Surveys, 1960 to 1991. JAMA 1994; 272: 205-211.

2 Seidell JC. Obesity in Europe: scaling an epidemic. Int J Obes Relat Metab Disord 1995; 19 (Suppl 3): S1-S4.

3 Popkin BM. The nutrition transition in low-income countries: an emerging crisis. Nutr Rev 1994; 52: 285-298. 
4 Flegal KM, Carroll MD, Kuczmarski RJ, Johnson CL. Overweight and obesity in the United States: prevalence and trends, 19601994. Int J Obes Relat Metab Disord 1998; 22: 39-47.

5 Troiano RP, Flegal KM, Kuczmarski RJ, Campbell SM, Johnson CL. Overweight prevalence and trends for children and adolescents: the National Health and Nutrition Examination Surveys, 1963 to 1991. Arch Pediatr Adolesc Med 1995; 149: 1085-1091.

6 Jousilahti P, Tuomilehto J, Vartiainen E, Pekkanen J, Puska P. Body weight, cardiovascular risk factors, and coronary mortality. 15year follow-up of middle-aged men and women in eastern Finland. Circulation 1996; 93: 1372-1379.

7 Carey VJ, Walters EE, Colditz GA, Solomon CG, Willett WC, Rosner BA, Speizer FE, Manson JE. Body fat distribution and risk of non-insulin-dependent diabetes mellitus in women. The Nurses' Health Study. Am J Epidemiol 1997; 145: 614-619.

8 Rissanen A, Heliövaara M, Knekt P, Reunanen A, Aromaa A, Maatela J. Risk of disability and mortality due to overweight in a Finnish population. BMJ 1990; 301: 835-837.

9 Han TS, Schouten JSAG, Lean MEJ, Seidell JC. The prevalence of low back pain and association with body fatness, fat distribution and height. Int J Obes Relat Metab Disord 1997; 21: 600-607.

10 Sarlio-Lähteenkorva S, Lahelma E. The association of body mass index with social and economic disadvantage in women and men. Int J Epidemiol 1999; 28: 445-449.

11 Allison DB, Zannolli R, Narayan KMV. The direct health care costs of obesity in the United States. Am J Public Health 1999; 89: 11941199.

12 Martínez-González MA, Martínez JA, Hu FB, Gibney MJ, Kearney J. Physical inactivity, sedentary lifestyle and obesity in the European Union. Int J Obes Relat Metab Disord 1999; 23: 1192-1201.

13 Crespo CJ, Smit E, Troiano RP, Bartlett SJ, Macera CA, Andersen RE. Television watching, energy intake, and obesity in US children: results from the third National Health and Nutrition Examination Survey, 1988-1994. Arch Pediatr Adolesc Med 2001; 155: 360-365.

14 Dallosso HM, James WPT. The role of smoking in the regulation of energy balance. Int J Obesity Relat Metab Disord 1984; 8: 365375.

15 Flegal KM, Troiano RP, Pamuk ER, Kuczmarski RJ, Campbell SM. The influence of smoking cessation on the prevalence of overweight in the United States. N Engl J Med 1995; 333: 1165-1170.

16 Molarius A, Seidell JC, Kuulasmaa K, Dobson AJ, Sans S, for the WHO MONICA Project. Smoking and relative body weight: an international perspective from the WHO MONICA Project. $J$ Epidemiol Community Health 1997; 51: 252-260.

17 Heini AF, Weinsier RL. Divergent trends in obesity and fat intake patterns: the American paradox. Am J Med 1997; 102: 259-264.

18 Troiano RP, Briefel RR, Carroll MD, Bialostosky K. Energy and fat intakes of children and adolescents in the United States: data from the National Health and Nutrition Examination Surveys. Am J Clin Nutr 2000; 72 (Suppl 5): 1343S-1353S.

19 Zhang J, Temme EHM, Sasaki S, Kesteloot H. Under- and overreporting of energy intake using urinary cations as biomarkers: relation to body mass index. Am J Epidemiol 2000; 152: 453462.

20 Harnack LJ, Jeffery RW, Boutelle KN. Temporal trends in energy intake in the United States: an ecologic perspective. Am J Clin Nutr 2000; 71: 1478-1484.

21 Nielsen SJ, Siega-Riz AM, Popkin BM. Trends in energy intake in U.S. between 1977 and 1996: similar shifts seen across age groups. Obes Res 2002; 10: 370-378.

22 Lissner L, Heitmann BL. Diatery fat and obesity: evidence from epidemiology. Eur J Clin Nutr 1995; 49: 79-90.

23 Hill JO, Prentice AM. Sugar and body weight regulation. Am J Clin Nutr 1995; 62 (Suppl 1): 264S-274S.

24 Tunstall-Pedoe $\mathrm{H}$, for the WHO MONICA Project. The World Health Organization MONICA Project (monitoring trends and determinants in cardiovascular disease): a major international collaboration. J Clin Epidemiol 1988; 41: 105-114.

25 Molarius A, Kuulasmaa K, Sans S, for the WHO MONICA Project. Quality assessment of weight and height measurements in the WHO MONICA Project, 1998. Available from URL: http:// www.ktl.fi/publications/monica/bmi/bmiqa20.htmURN:NBN:fifel19991079.

26 Wolf HK, Kuulasmaa K, Tolonen H, Ruokokoski E, for the WHO MONICA Project. Participations rates, quality of sampling frames and sampling fractions in the MONICA Surveys, 1998. Available from URL: http://www.ktl.fi/publications/monica/nonres/nonres.htmURN:NBN:fi-fe19991076.

27 WHO MONICA Project. MONICA manual, part III: population survey, section 1: population survey data component, 1997. Available from URL: http://www.ktl.fi/publications/monica/manual/part3/iii-1.htmURN:NBN:fi-fe19981151.

28 WHO. Obesity: Preventing and managing the global epidemic. WHO Technical Report SERIES 894 World Health Organization: Geneva; 2000.

29 FAO. http://www.fao.org/waicent/faostat/agricult/fbs-e.htmAccessed 12 July 2000.

30 Waterhouse J, Muir CS, Corea P, Powell J (eds). Cancer incidence in five continents. IARC: Lyon; 1976.

31 Willett W. Implications of total energy intake for epidemiological analysis. In: Willett W (ed). Nutritional epidemiology. Oxford University Press: Oxford; 1990. pp 247-271.

32 Kuulasmaa K, Tunstall-Pedoe H, Dobson A, Fortmann S, Sans S, Tolonen $\mathrm{H}$, Evans A, Ferrario M, Tuomilehto J, for the WHO MONICA Project. Estimation of contribution of changes in classical risk factors to trends in coronary-event rates across the WHO MONICA Project populations: methodological appendix to a paper published in the Lancet, 2000. Available from URL: http://www.ktl.fi/publications/monica/earwig/appendix.htmURN: NBN:fi-fe19991356.

33 SAS Institute Inc. SAS OnlineDoc, version 8. SAS Institute Inc: Cary, NC, USA; 1999.

34 Nilsen SJ, Popkin BM. Patterns and trends in food portion sizes, 1977-1998. JAMA 2003; 289: 450-453.

35 Sasaki S, Kesteloot H. Value of Food and Agriculture Organization data on food-balance sheets as a data source for dietary fat intake in epidemiological studies. Am J Clin Nutr 1992; 56: 716-723.

36 Bobak M, Pikhart H, Rose R, Hertzman C, Marmot M. Socioeconomic factors, material inequalities, and perceived control in self-rated health: cross-sectional data from seven post-communist countries. Soc Sci Med 2000; 51: 1343-1350.

37 Palosuo H. Health-related lifestyles and alienation in Moscow and Helsinki. Soc Sci Med 2000; 51: 1325-1341.

38 Anderson GH. Sugars, sweetness, and food intake. Am J Clin Nutr 1995; 62 (Suppl 1): 195S-202S.

39 Willett WC. Is dietary fat a major determinant of body fat? Am J Clin Nutr 1998; 67 (Suppl 3): 556S-562S.

40 Bray GA, Popkin BM. Dietary fat intake does affect obesity. Am J Clin Nutr 1998; 68: 1157-1173.

\section{Appendix}

\section{Participating centres of the WHO MONICA Project}

Australia-University of Western Australia, Nedlands: MST Hobbs, K Jamrozik, PL Thompson, BK Armstrong; University of Newcastle, Newcastle: A Dobson, S Leeder, H Alexander, R Heller.

Belgium - Ghent State University, Ghent: G De Backer, I De Craene, F van Onsem, L van Parys, S De Henauw, D De Bacquer. 
China-Beijing Heart, Lung and Blood Vessel Research Institute, Beijing: Wu Zhaosu, Wu Yingkai, Yao Chonghua, Zhang Ruisong.

Czech Republic-Institute for Clinical and Experimental Medicine, Prague: Z Škodová, Z Píša, L Berka, Z Cícha, J Cerovská, R Emrová, M Hoke, M Hronkova, J Pikhartová, R Poledne, P Vojtíšek, J Vorlicek, E Wiesner, D Grafnetter.

Denmark - Centre of Preventive Medicine (The Glostrup Population Studies) Copenhagen University: M Schroll, M Kirchhoff, A Sjol, K Korsgaard Thomsen, M Madsen, TJ Joergensen.

Finland-National Public Health Institute, Helsinki: J Tuomilehto, P Puska, A Nissinen, E Vartiainen, H Korhonen, P Jousilahti, P Pietinen.

France - National Institute of Health and Medical Research (INSERM U258) Paris: P Ducimetiere, JL Richard, A Bingham, T Lang; National Institute of Health and Medical Research, Toulouse: J Ferrieres, JP Cambou, JB Ruidavets, MP Branchu, V Delmas, P Rodier; Department of Epidemiology and Public Health, INSERM U508, Pasteur Institute, Lille: P Amouyel, D Cottel, MC Nuttens, N Marécaux, J Dallongeville, J-L Salomez, M Montaye ${ }^{1}$, C Steclebout.

Germany-Bremen Institute for Prevention Research and Social Medicine, Bremen: E Greiser, B Herman, G Stüdemann; GSF-Institute for Epidemiology, Munich and Institute for Epidemiology and Social Medicine, University of Münster: U Keil, J Stieber, A Döring, B Filipiak, U Härtel, HW Hense; Centre for Epidemiology \& Health Research, Berlin: W Barth, L Heinemann, A Assmann, S Böthig, G Voigt, S Brasche, D Quietzsch, E Classen.

Iceland-Heart Preventive Clinic, Reykjavik: U Agnarsson, II Gudmundsdottir, N Sigfusson, I Stefansdottir, Th Thorsteinsson, H Sigvaldason; Institute of Cardiology, Regional Hospital, Udine: D Vanuzzo, GA Feruglio, L Pilotto, GB Cignacco, M Scarpa, R Marini, G Zilio, M Spanghero, G Zanatta; Research Centre on Chronic Degenerative Diseases of the University of Milan: GC Cesana, M Ferrario, R Sega, P Mocarelli, G De Vito, F Valagussa.

Lithuania-Kaunas Medical Academy, Institute of Cardiology: J Bluzhas, S Domarkiene, A Tamosiunas, R Reklaitiene.

New Zealand-University of Auckland: R Beaglehole, RT Jackson, R Bonita, AW Stewart, D Mahon, W Bingley.

Poland-Institute of Public Health, Collegium Medicum, Jagiellonian University, Kraków: A Pajak, J Sznajd, E Kawalec, T Pazucha, M Malczewska, I Mórawska; National Institute of Cardiology, Warsaw, Department of Cardiovascular Epidemiology and Prevention: S Rywik, G Broda, A Waoekiewicz, E Sygnowska, B Jasinski, P Kurjata.

Russian Federation - National Research Centre for Preventive Medicine, Moscow: T Varlamova, A Britov, V Konstanti- nov, T Timofeeva, A Alexandri, O Konstantinova; Institute of Internal Medicine, Novosibirsk: Yu P Nikitin, S Malyutina.

Spain - Institute of Health Studies, Department of Health and Social Security, Barcelona: S Sans, I Balaguer-Vintró, Ll Balañá, G Paluzie, D Ruiz.

Sweden-Göteborg University, The Cardiovascular Institute: L Wilhelmsen, A Rosengren, S Johansson, A Dotevall, G Lappas; Kalix Hospital, Department of Medicine: V Lundberg, E Jägare-Westerberg; Kiruna Hospital, Department of Medicine: T Messner; Umeå University Hospital, Department of Medicine: K Asplund, B Stegmayr.

Switzerland-Institute of Social and Preventive Medicine, University of Lausanne: M Rickenbach, V Wietlisbach, D Hausser, B Tullen, F Paccaud; Institute of Social and Preventive Medicine, University of Zurich: F Gutzwiller, Department of Social Affairs, Cantonal Health Office of Ticino: F Barazzoni, F Mainieri, G Domenighetti.

United Kingdom - The Queen's University of Belfast, Northern Ireland: AE Evans, EE McCrum, T Falconer, S Cashman, C Patterson, M Kerr, D O'Reilly, A Scott, M McConville, I McMillan; University of Dundee, Scotland: H Tunstall-Pedoe, WCS Smith, R Tavendale, I Crombie, C Brown, M Shewry, MK Hannah; Royal Infirmary, Glasgow, Scotland: C Morrison.

USA-Stanford Center for Research in Disease Prevention, Stanford University, California: SP Fortmann, A Varady, MA Winkleby, D Jatulis, M Hull.

Yugoslavia-Novi Sad Health Centre: M Planojevic, D Jakovljevic, A Svircevic, M Mirilov, T Strasser.

MONICA Management Centre - World Health Organization, Geneva: S Mendis, I Martin, I Gyarfas, Z Pisa, SRA Dodu, S Böthig, MJ Watson, M Hill.

MONICA Data Centre - National Public Health Institute, Helsinki, Finland: K Kuulasmaa, J Tuomilehto, A Molarius, E Ruokokoski, V Moltchanov, H Tolonen; MONICA Steering Committee: J Tuomilehto (Chair), H Wolf (Publications Coordinator), A Dobson, S Sans, H Tunstall-Pedoe, S Mendis (WHO, Geneva), K Kuulasmaa (KTL, Helsinki, Finland); Previous Steering Committee Members: P Amouyel, K Asplund, R Beaglehole, A Evans, M Ferrario, SP Fortmann, F Gutzwiller, M Hobbs, U Keil, A Menotti, A Pajak, P Puska, SL Rywik, and former Chiefs of CVD/HQ, Geneva (listed above), A Shatchkute (WHO, Copenhagen), V Zaitsev (WHO, Copenhagen); Former Consultants: FH Epstein (Zürich, Switzerland), M Feinleib (Bethesda, USA), MJ Karvonen (Helsinki, Finland), Z Pisa (Prague, Czech Republic), RJ Prineas (Minneapolis, USA), OD Williams (Birmingham, AL, USA);

Former Consultants: MJ Karvonen (Helsinki, Finland), RJ Prineas (Minneapolis, USA), M Feinleib (Bethesda, USA), FH Epstein (Zürich, Switzerland), Z Pisa (Prague, Czech Republic), OD Williams (Birmingham, AL, USA). 